\title{
Urdimento
}

\section{PROCEDIMENTOS ESTRATÉGICOS OPERADOS PELO ERRO GRUPO NAS INTEVENCÕES URBANAS DESVIO E ENFIM UM LIDER}

\author{
Pedro Diniz Bennaton 1
}

\section{Resumo}

$\mathrm{O}$ artigo tem como foco principal descreveralgunsprocedimentosestratégicos de invasão, ocupação e deslocamento, utilizados em duas intervenções de teatro de rua do ERRO Grupo. Através de relatos do grupo sobre duas experiências práticas, Desvio (2006) e Enfim um Líder (2007), das teorias de Richard Schechner e dos relatos de experiências situacionistas no espaço urbano, esta análise contribui para a compreensão de procedimentos operacionais e de processos criativos de ação urbana.

Palavras-chave: estratégias, performance, intervenção urbana

\begin{abstract}
The main focus of this article is to describe some estrategical procedures of invasion, ocupation and displacement, used in two of the ERRO Grupo's street theater interventions. Through reports of the two group's practical experiences, Desvio (2006) and Enfim um Lider (2007), of the Richard Schechner's theories and of the situacionists' descriptions of experiences on the urban space, this analysis contributes to compreehend operational procedures and creative processes of urban actions.
\end{abstract}

Keywords: estrategies, performance, urban intervention

Na concepção dos situacionistas² e de seus procedimentos estratégicos de ação, como a interferência mútua entre dois ambientes de experiência, por gestos e palavras que adquirem outros significados, pela criação de linguagens secretas, com senhas, pela inclinação ao jogo, pela união de expressões independentes, a deriva e a psicogeografia, o movimento transforma as relações e cria elementos transviados, justapostos e livres, que constroem uma esfera dinâmica no cotidiano do espaço urbano. Portanto, quando constroem situações, ou quando propõem estratégias para a criação dessas, os situacionistas abrem uma gama de possibilidades para modificar as condições determinantes dos fluxos urbanos e criar ambientações em plena rua, assim como propõe o Environmental Theater, de Richard Schechner, teórico da performance da New York University.

1Pedro Diniz Bennaton é diretor teatral, dramaturgo, integrante fundador do ERRO Grupo e mestre em teatro pelo PPGT-UDESC, com a dissertação

Deslocamento e Invasão: Estratégias de intervenção para a construção de situações urbanas de interferência nas relações cotidianas, sob orientação do prof. André Carreira. Como diretor teatral participou de projetos e festivais nacionais e internacionais.

${ }^{2} \mathrm{~A}$ Internacional Situacionista formada em 1957 pela junção entre a Internacional Letrista de Guy Debord e o Movimento Internacional por uma Bauhaus Imaginista, e a Sociedade Psicogeográfica de Londres (dito ter participado à época, mas inventado para ajudar os objetivos 


\section{Urdimento}

${ }^{2}$ (cont.)internacionalistas do grupo) realizou trabalhos artísticos e teóricos, políticos e agitadores, é oriunda de uma tradição de anti-arte utópica que recria as vanguardas artísticas com reputação de escândalos, crimes e subversão. Aproximadamente 70 integrantes fizeram parte do grupo, mas esse número oscilou entre 05 a 15 membros ao mesmo tempo, devido a constantes expulsões, com Guy Debord sendo 0 único a permanecer até o fim em 1972. (Internacional Situacionista, Antologia, 1997).

${ }^{3} 0$ ERRO Grupo, fundado no dia 13 de março de 2001 em Florianópolis/ $\mathrm{SC}$, pesquisa a união das linguagens artísticas e a intervenção da arte no cotidiano das pessoas. Atualmente, integram o ERRO, Pedro Bennaton, Luana Raiter, Michel Marques, Luiz Henrique Martins, Júlia Amaral, Ana Paula Cardozo e Priscila Zaccaron, aprofundando a pesquisa coletiva na invasão urbana, desenvolvendo suas práticas de teatro de rua, instalações, performances e intervenções. A página eletrônica do grupo pode servir como referência para mais informações, www. errogrupo.com.br.
Os situacionistas clamam por procedimentos estratégicos em constante movimento entre a experimentação e a práxis que possam abranger a grande variedade de possíveis áreas de manifestações no espaço urbano, demonstrando que a arte situacionista em si não existe, mas, sim, uma aproximação situacionista, ou seja, estratégias situacionistas de se lidar com a arte. Schechner ressalta que o potencial das performances urbanas permite "que as pessoas se encontrem" nas ruas para "flertar com a possibilidade da improvisação - de que o inesperado possa acontecer” (1976:197).

Em texto de 1955, Introdução a uma crítica da geografia urbana, os situacionistas afirmam que "a troca repentina de ambientes em uma mesma rua na distância de alguns metros" deve ser a lógica dos passeios sem razão para a experiência de uma série de ambientações, "a partir de condições de vivência", a partir da deriva. A deriva foi concebida para revolucionar o cotidiano. As ações para a realização da deriva seriam uma espécie de perambular ao acaso pelas ruas de uma cidade, como "um nomadismo urbano visionário", a experimentar "a intensidade da percepção". O praticante da deriva deveria aceitar as imprevisibilidades, deslocando-se para sinais, coincidências ou escolhas aleatórias que possam guiá-lo ao rumar de lugar a lugar, consciente "do itinerário como significado" e simbologia. (1997: 118)

Através de uma invasão no espaço com o uso do deslocamento através de outros espaços, o potencial do inesperado, do improvável, acontecer fica mais latente. A transformação eminente pela movimentação, ocupação e abrangência da ação em diferentes níveis espaciais, e relacionais, evidencia que o acaso é inerente à intervenção urbana. Esta deve articular o presente em suas estratégias para ir além na comunicação com as pessoas, na ruptura do cotidiano, para construir vínculos de aproximação entre a ação urbana e a rede social e espacial da cidade.

Os trabalhos do ERRO Grupo possuem rastros das práticas situacionistas e das teorias de Schechner. Integram o repertório do grupo sete peças de rua, Adelaide Fontana (2001), Carga Viva (2002), Buzkashi (2004), Desvio (2006), Enfim um Líder (2007) e Escaparate (2008), assim como diversas performances e intervenções urbanas. Neste artigo sobre os procedimentos estratégicos de invasão, ocupação e deslocamento pesquisados pelo ERRO, o foco se restringe às suas operações em duas obras: Desvio ${ }^{4}$ e Enfim Um Líder ${ }^{5}$.

Em abril de 2006, o ERRO Grupo foi contemplado com o Prêmio FUNARTE de Teatro Myriam Muniz, com o patrocínio da Petrobras, para a montagem de Desvio, o qual o grupo estava pesquisando e ensaiando havia um ano e quatro meses. Este prêmio, em forma de recurso financeiro não só viabilizou a construção do espetáculo, como a realização de uma temporada de estréia em novembro do mesmo ano e ainda oportunidade de ensaiarmos durante três meses nas ruas da cidade no período noturno e nos finais de semana. 


\section{Urdimento}

Desvio é uma intervenção urbana que busca o limite da dúvida, que suas ações e cenas se desloquem entre a realidade e a ficção, em percurso no cenário concreto do centro das cidades, no qual o público é convidado a experimentar a preparação da representação de um assassinato que poderá ser interpretado por diferentes vias ao longo de sua trajetória, de seu deslocamento. Como uma ação artística nas ruas, re-significa as estruturas físicas e simbólicas deste espaço, questionando-as, expondo-as. Nas suas ações, quando o ator lê as vitrines das lojas nas ruas ridicularizando os meios mercadológicos ou quando a atriz faz sinais para as câmeras de vigilância instaladas nas ruas durante o percurso das cenas, o público é inserido no universo vivenciado no enredo da peça, e não mais como algo externo ao seu ambiente. A todo o momento a ação se instaura nos lugares e logo depois se dissipa. A cada cena um novo espaço e este novo processo, os espaços são conquistados pelos atores junto ao público que se mobiliza em deslocar-se com a ação, a invadir e ocupar cada novo território.

Entretanto, em Desvio, o que move essa situação é a preparação da representação de um assassinato que cria um ambiente desconfortável, e ao mesmo tempo onírico, onde a experiência da morte sempre anunciada não se dá vias de fato, mas vias de experiência. Como Schechner expõe, em seu livro Performance Theory, o enredo da intervenção urbana é importante para adquirir seu potencial de ritual, mesmo que esta seja oriunda apenas de uma imagem, de uma situação.

É necessário frisar que apesar de Desvio estar aberto a situações imprevisíveis, existe um roteiro planejado e ensaiado em seus mínimos detalhes, mesmo que a qualquer momento o elenco possa sair do planejamento estipulado, deve retornar em algum ponto para seguir adiante. Tanto nos casos de intervenções radicais, como a que tivemos em Curitiba, no dia 28 de março de 2007, quando, em uma cena do espetáculo na qual uma atriz gritava "Pega, pega!" à outra atriz, que está perseguindo um ator a uns vinte metros do público, foi capturada e imobilizada pelo pescoço por um transeunte sendo necessário que o público gritasse de longe que se tratava de uma peça, pois, o elenco não saiu do jogo proposto pelo espetáculo. Como em participações como a de um homem em uma apresentação em Florianópolis, no dia 15 de novembro de 2006, que ergueu o ator, que gritava "É maravilhoso!", fez coreografias, desferiu socos e chutes em direção ao elenco e agrediu verbalmente um dos atores, que dorme em praticamente todas as cenas de Desvio, após sussurrar no ouvido deste ator, repetitivamente, a seguinte frase: "É mentira".

Como uma experiência de presença, mais do que intelectual, o percurso, o deslocamento, possibilita à intervenção estar sempre em movimento, não só o óbvio movimento físico, mas também em movimento de experiência. A invasão repetitiva faz com que Desvio esteja sempre entre a acessão e a queda. O
${ }^{4}$ Desvio(2006) apresenta a representação de um assassinato em um percurso pelas vias públicas. Em 2006 ganhou o Prêmio FUNARTE de Teatro Myriam Muniz com 0 patrocínio da Petrobras. Em 2007, participou do Festival de Teatro de Curitiba, Mostra Myriam Muniz FECATE, Temporada SESC Campinas de Teatroe Festival Internacional de Teatro de São José do Rio Preto 2007. A concepção e direção geral são de Pedro Bennaton.

${ }^{5}$ Enfim um Líder (2007) intervenção urbana de três dias que traz para os centros urbanos a expectativa da chegada de um líder, mais informações no site: www.enfimumlider.com. br. Estreou nos dias 19, 20 e 21 de dezembro de 2007 no Centro de Florianópolis e realizou 09 apresentações nas cidades de Palhoça, Biguaçu, São José e Florianópolis, durante 0 ano de 2008. Foi contemplado em outubro de 2007 pelo Prêmio FUNARTE de Teatro Myriam Muniz com o patrocínio da Petrobras. Seu roteiro de ações se norteia pela pesquisa realizada nos ensaios em sala, nos ensaios de longas observações no espaço urbano, assim como se inspira em diversas obras da dramaturgia como Esperando Godot de Samuel Beckett, 


\section{Urdimento}

${ }^{5}$ (cont.)The Speakers de Heathcote Williams, As Cadeiras e O Líder de Eugéne Ionesco, e também por panfletos religiosos e livros como A Arte da Guerra de Sun Tzu e Manifestos Neoistas de Stewart Home. Participam do elenco os atores João Garcia, Luana Raiter, Luiz Henrique Martins, Sarah Ferreira, Rodrigo Sember e Tama Ribeiro Os autores são Luana Raiter e Pedro Bennaton, a direção de arte e o design gráfico são de Júlia Amaral e Luana Raiter e a direção de Pedro Bennaton. deslocamento, sua ocupação de cada novo espaço, de cada novo elemento urbano, faz com que o público e o elenco e suas relações estejam em uma restauração repetitiva. Através deste jogo repetitivo, tanto na invasão de cada espaço, quanto na repetição das cenas de ensaio da representação do assassinato, a intervenção está em reconstrução e rearranjo constante das ações e relações dos atores e também das pessoas que participam do percurso. Desta forma, propõe ao público uma situação de comportamento restaurado, que é identificado por Schechner, como seqüências de comportamento "organizadas de acontecimentos, roteiro de ações, textos conhecidos, movimentos codificados" (1995:36). A repetição das cenas faz com que o público reorganize sua participação e experiência, para assim, confiante, restaurar seu comportamento, modificando seu ângulo de visão e, ou, interferindo nos acontecimentos, pois os vínculos do elenco e do público se aprofundam e são vivenciados propositalmente pelo jogo espacial e inesperado da intervenção urbana.

O treinamento do elenco realizado pelo grupo busca apropriar-se do ambiente urbano, absorvendo-o, permitindo e valorizando o acaso como constituinte importante para uma cena aberta a intervenções. Este exercício está relacionado também a um tipo de presença almejada pelo ERRO para estabelecer vínculos de participação do público durante suas ações. Schechner elabora uma série de exercícios para criar confiança entre os atores, para adentrar ambientes de risco eminente e produzir o que ele chama de presença:

...Essa presença está relacionada com a noção de eventualidade. Em outras palavras, quando o espectador percebe que o ator pode não só mudar o que está fazendo, mas que pode também ser o dono dessa mudança, que não tem que mudar, mas pode eventualmente fazê-lo, nesse momento o ator tem presença. Em compensação, se o espectador sente que toda e qualquer mudança apavora o ator e corre o risco de destruir a representação, não há presença. Na verdade, o ator brinca com o perigo, e o perigo por ele gerado é que cria a presença (2001:12).

Esse perigo pode ocorrer no momento de invasão em um espaço urbano em razão de imprevistos que o ator está sujeito. Portanto, seu desempenho está ligado à sua confiança de acordo com Schechner, que ao refletir sobre a confiança no trabalho do ator nos direciona para alguns exercícios, como o guia cego, onde os olhos de algumas pessoas são vendados e elas começam a dirigir as outras.

Os exercícios de confiança são um treinamento, segundo Schechner, para o ator estar disponível a interferências, interações e integrações, que possam ocorrer durante os instantes da ação. Podem existir variações dentro das necessidades de cada situação a ser construída que permitem ao ator estar em desconforto, habitar o desconhecido, que o possibilita a extrair diferentes níveis 
de confiança como, por exemplo, permanecer sem o sentido da visão e treinar diversas ações, como correr, pular, etc, nessa condição. Através dessa consciência corporal e espacial adquirida, ao lidarem com estratégias de intervenção no espaço urbano, os atores podem experimentar, nas palavras de Schechner, que "nada aproxima um grupo tão rapidamente ou com tanto entusiasmo do que uma ação tomada coletivamente em uma atmosfera de risco" (1997:312).

Em Florianópolis, Desvio realizou quatro percursos diferentes no centro. Foram percorridas no total 22 ruas e 2 praças, possibilitando ao grupo experimentar a ocupação das ações em diversos cenários arquitetônicos. As ações guiam seu público em um lúdico crime que poderá ser interpretado por diferentes caminhos ao longo de seu deslocamento em jogo.

Ao buscarmos diferentes experiências com o público, também passamos por situações inesperadas, algumas antes mesmo de sua primeira apresentação. Se para alguns a Desvio começa na rua, no momento da apresentação, para outros essa experiência tem início dentro de casa, por meio de uma carta enviada por uma personagem. A carta representa uma cena e traz um desabafo da personagem, que convida o destinatário a encontrá-la em um ponto do centro, com local e hora marcados.

Na temporada de estréia com 12 apresentações foram enviadas 1.500 cartas nominais a destinatários residentes em Florianópolis que tiveram seus endereços escolhidos aleatoriamente. As interpretações do conteúdo da carta foram distintas, inclusive 56 pessoas entraram em contato com a polícia, de acordo com os oficiais da $5^{\text {a }}$ delegacia de polícia da cidade. Antes da estréia, a atriz que interpreta a personagem, Ana Contra-atriz, escreveu e mandou a carta, com seu próprio endereço como remetente, recebeu a visita de policiais civis em sua casa, que averiguavam se a pessoa chamada Ana Contra-Atriz era uma criminosa.

A polícia militar também marcou presença nas primeiras apresentações de Desvio. Na primeira apresentação a atriz que recebe o público convidado pela carta foi surpreendida por um policial à paisana que agressivamente a imobilizou e levou-a para o meio da rua, onde, segundo testemunhas presentes no local, teria apontado um revólver nas suas costas. O policial gritava coisas como, "Cadê os outros?”, "A quadrilha foi destruída!", "Já era para vocês!". Enquanto ele levou a atriz até o meio da rua, uma viatura policial, com suas luzes e sirene ligadas, chegou com dois policiais fardados. A atriz percebeu que o contra-regra que a acompanhava nessa ação estava entrando em contato com a produção e direção via rádio comunicador, e continuou no jogo dizendo que quem havia escrito a carta era sua irmã (a personagem Ana Contraatriz) que estava confusa, pois, o que de fato aconteceria era a representação 


\section{Urdimento}

de um assassinato. Os policiais queriam levar a atriz para a delegacia para interrogá-la, mas desistiram quando algumas pessoas chegaram com a carta em mãos para o início de Desvio.

Outra imprevisível intervenção partiu de uma menina de 9 anos, filha de catadores de papel que trabalham à noite no centro de Florianópolis, que assistiu aos ensaios gerais do grupo no espaço urbano, e resolveu atuar no dia da primeira apresentação. A garota teve seu primeiro contato com o teatro por meio desses ensaios realizados nas ruas no decorrer do processo de criação. Brincando com o elenco nos jogos na rua de criação para Desvio, ela se identificou com uma das personagens, decorou suas falas durante os ensaios, passando a atuar em algumas noites durante a temporada. Ela ainda passou a integrar o grupo nos momentos de confraternização antes e após as apresentações, porém em nenhum momento se estabeleceu como ela deveria atuar ou o que ela poderia fazer. A menina fazia o que bem entendia, carregava o assassino para o elenco durante as apresentações, falava textos que havia decorado, e saía de cena para brincar ou conversar com familiares e amigos enquanto a ação se desenrolava.

Ao trabalharmos com intervenções que se propõem a ocupar, invadir e deslocar as ações no espaço urbano, os elementos surpresa são absorvidos pelas ações do elenco e para isso estabelecemos a noção de que toda a cidade participa da história, em uma espécie de reenacment. O reenactment é uma reconstrução cênica para reviver algum momento específico, o que possibilita ao grupo buscar o que um ambiente propício para interferências. Como se estivessem no roteiro, ou como se estivessem agindo fora de algo planejado, alguns exercícios realizados nos ensaios foram utilizados na peça sob forma de releituras, mas sempre instaurando em cada rua, um ambiente provocado pelo reenactment, fazendo das intervenções e os elementos novos que apareciam no percurso urbano material para potencializar as ações de Desvio nas ruas.

Nas apresentações, apenas noturnas, a cidade quase vazia, sem o fluxo intenso de pessoas e veículos, o comércio fechado e as ruas calmas propiciam uma atmosfera onírica, aumentando o potencial de interatividade do espaço urbano, deixando-o mais penetrável, mais claro no sentido de visível, mais vulnerável a diálogos e encontros. A situação proposta pelo roteiro de ações interdita o encontro entre inalcançáveis lembranças passadas e fatais enredos que se adiam. Uma série de vínculos se estabelece entre aqueles que seguem o cortejo até a praça, partilhando com concentrada devoção a curiosidade coletiva. Nesse ambiente construído a partir das estratégias de ação no espaço urbano, invasão, deslocamento e ocupação, o elenco movimenta-se e fala de modo familiar com o espaço. Talvez por isso muitos transeuntes embarcam na experiência e mesmo sem serem convidados acrescentam falas e interagem como parte do roteiro. 
É importante frisar que a invasão aqui não pode ser considerada como tal, apenas, quando carrega um fator ilegal. Seja este espaço o corpo de um transeunte surpreendido por um abraço, ou mesmo pela invasão da ficção por meio de cartas em casas de desconhecidos, tanto a invasão quanto a ocupação se constroem pelo nível de afrontamento, estranhamento e invasão física dos atores em territórios que não são pré-estabelecidos ou delimitados para a representação. As diversas formas de se ocupar ou invadir um espaço derivam do reconhecimento e do enfrentamento, tanto com sua arquitetura, suas vias de fluxo e controle, assim como de suas leis.

No desenrolar da performance a tentativa é que os prédios, as esquinas, as quadras, os elementos do espaço podem se compor inteiramente como cenário re-significado enquanto intermediário da relação ator-platéia em que todos, atores, arquitetura e público, estão imersos. Conseqüentemente, diferentemente do conceito de espectadores que apenas acompanham, ou esperam passivamente sentados, impõe-se a noção dos expectadores, como cúmplices ou testemunhas que possuem expectativas, interessados em como é ou será um crime, de um assassinato, no caso específico da situação de Desvio, como participantes, ou vivenciadores no termo dos situacionistas.

Quanto a essas questões entre cenário urbano e ficção cênica, ou da experiência entre atores e público, não é possível considerar o trajeto em que a intervenção percorre ligado à experiência do flâneur de Baudelaire, analisado por Walter Benjamin, pois neste ponto crucial a ação não pretende perambular na heterogênea massa urbana como no conforto de suas casas, mas sim a um deslocamento coletivo guiado através do estranhamento de observar a ilusão, o espetáculo, como a parte principal de nossas interpretações e relações.

Em janeiro de 2007, almejando explorar os procedimentos de invasão, ocupação e deslocamento de forma diluída e dilatada, o ERRO definiu como seu mais novo projeto uma intervenção urbana de três dias, Enfim um Líder.

Esta intervenção ocorre ao redor de uma única situação: a expectativa da chegada de um líder, onde a situação dilatada ao longo do tempo é minimamente influenciada pela dramaturgia, conflito, cenografia, narrativa e personagens, ou seja, menos contaminada possível por elementos teatrais. Através de procedimentos oriundos da noção da performance, como a presentificação dos atores e o distanciamento das convenções que amarram a linguagem artística e seus formalismos, o grupo constrói o texto e as ações em diálogo direto com as pessoas e o espaço.

Partindo do pressuposto situacionista de que o imaginário de uns pode se tornar real para outros, Enfim um Líder aborda a utópica imagem ou não de um líder, virtualmente real, criando um percurso midiático de espera

Dezembro $2008-\mathrm{N}^{\circ} 11 \quad$ Procedimentos estratégicos operados pelo Erro Grupo... Pedro Bennaton. 


\section{Urdimento}

para atingir diversas esferas da sociedade que acreditam no líder oculto, o marketing. A dilatação do tempo aumenta a possibilidade de algo inesperado acontecer abrindo as ações dos atores à interação do público, pela busca por uma maior abrangência de uma obra de arte na cidade. $\mathrm{O}$ acontecimento se apropria de meios de marketing, como carros de som, pichações, lambelambes, adesivos e programas de tv e rádio, para ampliar o alcance da situação e divulgarem a chegada do líder, não uma apresentação teatral. Enfim um Líder não trata somente da figura de liderança, mas trata sobre como se constrói um discurso atualmente e de quais meios são necessários para se criar, fabricar, um discurso verdadeiro em uma sociedade do espetáculo, segundo Debord, regido pelas estruturas do biopoder, que, de acordo com Foucault, constroem nossos discursos e nosso cotidiano.

Com a ação na rua por um longo período de tempo e a utilização de ferramentas de marketing que invadem nosso cotidiano, cria-se uma dramaturgia situacional que consiste na espera, na divulgação e na organização de uma recepção a um líder que chegará, ambicionando construir um ambiente de espera geral na cidade. Se nada existe fora de sua espetacularização, como aponta Debord, o anúncio da chegada do líder faz com ele exista antes mesmo de sua aparição. O público, os fiéis, os espectadores, que esperam e sonham com sua chegada, também ajudam a construir esse ídolo atemporal.

Neste ponto o grupo teve uma tangência em sua pesquisa, ao invés de operar com as estratégias de deslocamento e invasão em matrizes de ações cerradas, a princípio, e estruturadas em diálogos, o ERRO experimentou com Enfim um Lider algo mais relacionado aos happenings de Allan Kaprow e, até, do Teatro Invisível de Augusto Boal, operando as estratégias com uma matriz totalmente aberta à intervenção do público. A ação acontece na intervenção do público, sem diálogos pré-estabelecidos, com somente ações originadas, apenas, de uma matriz geral da situação de expectativa no espaço urbano.

Os atores limpam o espaço, decoram e transformam o espaço, atraindo o público, não apenas para a expectativa da chegada do líder, mas especialmente para a transformação do ambiente urbano, realizando ações que jogam com as estruturas de poder da cidade aos moldes do Environmental Theater de Schechner, que consiste em criar e recriar ambientes durante a ação performática. Os atores lidaram com uma espécie de improvisação a longo prazo, pois, as interações aconteciam durante os dias de ações com as mesmas pessoas que também trabalhavam no espaço. Dessa forma foi provocada uma espécie de ebulição ao redor da situação proposta pela intervenção urbana, o que elevou as possibilidades de transformação, de abertura para o imprevisível. 
O roteiro aberto é uma linha de ações de recepção, organização e propagação da própria situação da intervenção urbana e todos os seus diálogos, com exceção do discurso, são criados instantaneamente. As ações acontecem organizadas por uma logística e por uma narrativa nos meios de comunicação e na rua, mas é a interação e a reação integrada à ação cênica que geram seu texto propriamente oral. Por uma longa duração, se sucedem inúmeras ações, cada ação é um fragmento de um todo, mas, através de uma única ação: esperar o líder. Em Desvio, por exemplo, os procedimentos estratégicos de intervenção urbana, deslocamento e invasão, foram utilizados através de ações que acontecem freneticamente a todo instante em um longo espaço percorrido em diversos locais e, em Enfim um Líder, foram modificados para operarem com uma longa duração através de ações que acontecem com intervalos, porém em um espaço comprimido.

As estratégias de invasão e deslocamento estão presentes em Enfim um Líder não apenas, nas ações de decoração, limpeza e organização do espaço que são realizadas para deixar adequado o espaço de chegada do líder, mas nas apropriações dos meios de marketing. Seja pelo anúncio da chegada do líder, realizado por carro de som durante até dez horas por apresentação nas ruas da cidade ou pelos cartazes em off-set colados nos muros dos bairros, panfletos, faixas, e outros, onde a frase Enfim um Líder, o alívio e a expectativa da possibilidade de transformação, está sempre presente.

A escolha da relação entre a figura anônima do líder com a situação proposta pela ação de espera não foi aleatória. O grupo enfrentou diversos obstáculos em utilização do espaço urbano e nas interações com o público. Durante sua estréia, nos dias 19, 20 e 21 de dezembro de 2007, uma manifestante evangélica e, ou, com problemas psicológicos como nos foi informado pela polícia, que no terceiro dia ficou cerca de seis horas no espaço de apresentação, violentamente destruiu quase todo o cenário e a decoração colocada durante as cenas de Enfim um Líder. Aos berros clamava por outra pessoa que não era o líder. Como ela tentou agredir os atores que não pararam a ação cênica, mas tentaram acalmá-la, pessoas do público acharam que era tudo ficção. Isso dificultou o processo de trabalho em grupo, uma das integrantes indicou que não desejaria mais participar das apresentações, pois achava que poderíamos estar sob eminente risco de vida em nossas ações na rua, especificamente pela sua abertura, pela exploração do inconsciente coletivo ao questionar lideranças estabelecidas pela massa social e pelas suas ações completamente permeáveis pela realidade.

Outra dificuldade foi a de nós mesmos convencionarmos a pesquisa do grupo, pois, ao provocarmos imprevisibilidades no espaço urbano também objetivávamos que o público tivesse a noção de que o espaço estava aberto ao 


\section{Urdimento}

imprevisível. No caso da intervenção da manifestante evangélica o público estava dividido entre se aquilo estava, ou não, no roteiro de ação. O que era de fato real ficava manchado pela ficção próxima à realidade. Ou seja, estivemos a ponto de espetacularizar nossa própria produção de ruptura, nossa interação presencial. Nossa construção teatral no instante da ação foi compreendida por alguns como ensaiada, planejada, estruturada. Nossos cenários estavam sendo destruídos e os atores desorganizados, porém, as pessoas do público riam e elogiavam o naturalismo da cena.

Em uma apresentação do espetáculo na cidade de Palhoça (SC), um dos atores foi levado à delegacia, interrogado e pressionado a dizer ao major da PM da cidade quem era o líder, mesmo após inúmeras tentativas em dizermos para os oficiais que se tratava de teatro. O clima do interrogatório e do diálogo que acontecia no lado externo da delegacia teve ares de censura, os policiais argumentaram que a detenção se justificava, pois, havia um criminoso, de nome Papagaio, assaltante de bancos, foragido da penitenciária estadual, que estaria planejando um assalto, e esse poderia ser nosso líder já que no espaço de ação da peça estavam localizados todos os bancos do município. Após insistências em falarmos sobre o que estávamos fazendo na rua, que se tratava de uma situação construída para as pessoas participarem, jogarem, os policiais permitiram que voltássemos às ações no local específico e acompanharam o grupo até o espaço onde, criando uma cena à parte, cordialmente se apresentaram e se despediram do grupo e do público.

A diluição entre arte e vida é criada pelo acontecimento. Essa diluição se constrói, por exemplo, através de subversões realizadas pelo grupo de ações de divulgação da chegada do líder, como pichações, no estilo situacionista de arte criminosa, caracterizadas de acordo com o Código Penal como vandalismo e destruição de patrimônio, ou através das participações do público que criam o roteiro aberto em todas as apresentações. Em razão disso, Enfim um Líder possibilita ao ERRO uma experiência diferente de outras intervenções realizadas até então, pois, busca ultrapassar totalmente a fronteira ficcional para se transformar em um acontecimento real na cidade.

A população é chamada a participar dos preparativos para a recepção e para auxiliar na elaboração do discurso de recepção ao líder, ou seja, na construção de quem seria este líder. As ações se estruturam no espaço urbano colocando em discussão a razão pela qual todos nós buscamos um modelo em quem se inspirar e de nos guiar em nossas ações. É a crença e a dúvida que estão em jogo neste espetáculo, pois, se vivemos em uma sociedade espetacular pretendemos criar um deslocamento da propagação de informação para a criação de uma situação que envolva as pessoas, que talvez possam não acreditar mais no poder do teatro, mas ainda acreditam nos líderes ocultos: o marketing e o mercado. 
É possível através de procedimentos estratégicos interferir na rede de relações do espaço urbano, em seu ambiente e nas pessoas que ali transitam. O deslocamento, a ocupação e a invasão propiciam a reorganização e, ou, a desorganização de regras sociais e de formas de se vivenciar o espaço e especialmente a arte. Porém, quando o ambiente que se cria, a partir desses procedimentos, permite situações incontroláveis, desconhecidas, ou que poderiam ser perigosas para a integridade física do espaço, das pessoas e dos atores, cabe à práxis, em seu percurso, buscar dados mais precisos sobre técnicas de atuação na invasão e no deslocamento nas ruas, com o fim de construir laços de confiança e a capacidade "de ser dois em um, de se manter ao lado de si mesmo e de ver a si próprio” (SCHECHNER, 2001:12).

Ao utilizarem os procedimentos de invasão, deslocamento e ocupação, os atores são desafiados a selecionar uma série de posicionamentos diante das imprevisíveis integrações, interações e interferências das pessoas em suas ações, de forma que esse jogo de mão dupla pactue laços diretos entre os atores e o público. Ao proporcionar situações onde o público possa agir por vontade própria por meio de diferentes níveis de participação, as participações nas ações urbanas, como as integrações, interações e interferências, que possuem suas particularidades e modos de reação, constroem uma ação coletiva no espaço urbano.

\section{Referências bibliográficas}

BENJAMIN, Walter. Magia e técnica, arte e política: ensaios sobre a literatura e história da cultura. Tradução Sérgio P. Rouanet. In: Obras Escolhidas, v. 1, São Paulo: Brasiliense, 1985.

COHEN-CRUZ, Jan. Playing Boal: Theatre, therapy, activism. London: Routledge. 1994.

DEBORD, Guy. A Sociedade do Espetáculo. Lisboa: Afrodite, 1972.

KAPROW, Allan. Some recent happenings. New York: A Great Bear Pamphlet, 1966.

SCHECHNER, Richard. Ritual, play and performance. New York: Seabury, 1976.

. Performance Theory. New York: Routledge, 1988.

Environmental Theater. New York: Applause Books, 1994.

. The Future of Ritual - writings on culture and performance. London and New York: Routledge, 1995.

. A emoção que se quer despertar não é a do ator e sim a do espectador. Paris:

Seabury, 2001.

SITUACIONISTA, Internacional. Antologia. Tradução Júlio Henrique. Lisboa: Ed. Antígona, 1997. 